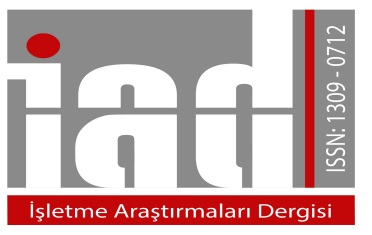

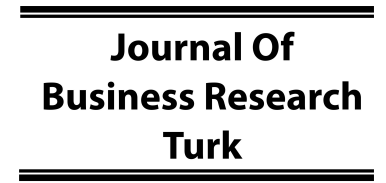

www.isarder.org

\title{
Yerel Finansal Raporlama Çerçevesi ve Büyük ve Orta Boy İşletmeler için Finansal Raporlama Standardı: Bir Literatür İncelemesi (2016 - 2017)
}

Framework for Local Financial Reporting and Financial Reporting Standard for Large and Medium Sized Entities: A Literature Review (2016 - 2017)

\author{
Can ÖZTÜRK \\ Çankaya Üniversitesi \\ İktisadi ve İdari Bilimler Fakültesi \\ İşletme Bölümü \\ Ankara, Türkiye \\ orcid.org/0000-0003-1587-4707 \\ cozturk@cankaya.edu.tr \\ Özet
}

Türkiye'de finansal raporlama Kamu Gözetimi Muhasebe ve Denetim Standartları Kurumu tarafından bağımsız denetim ve kamuya hesap verme yükümlülüğü kavramları çerçevesinde düzenlenir. Finansal raporlama amacıyla, bağımsız denetime tabi olup kamuya hesap verme yükümlülügü bulunan işletmeler Uluslararas1 Finansal Raporlama Standartları ile uyumlu Türkiye Finansal Raporlama Standartlarına (TFRS) tabidirler. Ancak, bağımsız denetime tabi olup kamuya hesap verme yükümlülüğü bulunmayan işletmeler için TFRS'yi veya Büyük ve Orta Boy İşletmeler için Finansal Raporlama Standardını (BOBİ FRS) kullanmaları yönünde iki seçenek bulunmaktadır. Bu çalışma, yakın zaman önce yayınlanan BOBİ FRS ve ondan önceki taslağı olan Yerel Finansal Raporlama Çerçevesi (YFRÇ) üzerine hakemli dergilerde yayınlanan makalelere ilişkin bir literatür incelemesine odaklanmıştır ve gelecekteki araştırmalar için öneriler sunmaktadir.

Anahtar Kelimeler: BOBİ FRS, YFRÇ, Türkiye, Finansal Raporlama, Literatür İncelemesi

\section{Abstract \\ In Turkey, financial reporting is regulated by Turkish Public Oversight,} Accounting and Auditing Standards Authority within the framework of the concepts of independent audit and public accountability. For the purpose of financial reporting, entities that are subject to independent audit and publicly accountable are subject to Turkish Financial Reporting Standards (TFRS) that are in compliance with International Financial Reporting Standards; however, entities that are not publicly accountable but subject to independent audit have two options either to use TFRS or 
Financial Reporting Standard for Large and Medium Sized Entities (FRS for LMEs). This paper focuses on a literature review related to the papers published in referred journals on the recently published FRS for LMEs and its draft predecessor which was called as Framework for Local Financial Reporting (FLFR) and offers suggestions for future research.

Keywords: FRS for LMEs, FLFR, Turkey, Financial Reporting, Literature Review

\section{GİRIŞ}

Türkiye'de finansal raporlama, Kamu Gözetimi Muhasebe ve Denetim Standartları Kurumu (KGK) tarafından bağımsız denetim (independent audit) ve kamuya hesap verme yükümlülüğü (public accountability) çerçevesinde yürütülmektedir. $\mathrm{Bu}$ amaçla, bağımsız denetime tabi olup kamuya hesap verme yükümlülüğü bulunan işletmeler, finansal tablolarını Uluslararası Finansal Raporlama Standartları (UFRS) ile uyumlu Türkiye Finansal Raporlama Standartlarına (TFRS) göre hazırlamak ve sunmak zorundadır. Ancak, bağımsız denetime tabi olup kamuya hesap verme yükümlülüğü bulunmayan işletmeler, finansal tablolarını KGK'nın sunduğu iki seçenekli yaklaşıma göre hazırlamakla yükümlüdür. Bu yaklaşıma göre söz konusu işletmeler, finansal tablolarını (1) TFRS'ye veya (2) Büyük ve Orta Boy İşletmeler için Finansal Raporlama Standardına (BOBİ FRS) göre hazırlayabilirler.

KGK tarafindan Kasım 2015 tarihinde taslak olarak Yerel Finansal Raporlama Çerçevesi (YFRÇ) adıyla yayınlanan ve yoruma açılan BOBİ FRS, alınan yorumlar ve yapılan düzenlemeler sonucunda 29 Temmuz 2017 tarihinde yayınlanmıştır (KGK, 2017). Söz konusu standart, Bölüm 9 Finansal Araçlar ve Özkaynaklar kapsamında TMS 32 Finansal Araçlar - Sunum standardına yaptığı atıf dışında kendine özgü bir standarttır (Öztürk, 2017). Taslaktan sonra yapılan düzenlemeler sonucunda Maden Kaynaklarının Araştırılması ve Değerlendirilmesine (Bölüm 8), Ara Dönem Finansal Raporlamaya (Bölüm 24) ve Yüksek Enflasyonlu Ekonomilerde Finansal Raporlamaya (Bölüm 25) ilişskin muhasebe politikalarının eklenmesiyle 27 Bölümden oluşmaktadır.

BOBİ FRS, Türkiye muhasebe uygulamaları açısından önemli bir gelişmedir. Bağımsız denetime tabi olup kamuya hesap verme yükümlülüğü bulunmayan ve de TFRS'yi uygulamayı tercih etmeyen işletmelerin finansal tablolarının yatırımcılar ve kredi verenler tarafindan anlaşılmasını, gerçeğe uygun sunumu, finansal bilgi ihtiyacını ve finansal tabloların karşılaştırılabilir olmasını sağlayan bir finansal raporlama standardidir.

Bu çalışmanın amacı; BOBİ FRS'nin taslak olarak tartışmaya açıldığı dönemi de kapsamak üzere 2016 ve 2017 yıllarında gerek BOBİ FRS'nin taslağını oluşturan YFRÇ'ye gerekse BOBİ FRS'nin yayınlandığı tarihten itibaren geçen beş aylık süreye ilişkin bir literatür incelemesi yaparak son iki yılda bu konu ile ilgili olarak hakemli dergilerde yayınlanan makaleleri (1) tespit etmek; (2) incelemek, (3) araştırma türlerine ve konularına göre sınıflandırmak, (4) kapsamını ortaya koymak, (5) makalelere yapılan atıfları raporlamak ve (6) bu konuda yazılabilecek yeni makalelere yönelik önerilerde bulunmaktır.

Çalışmanın ikinci bölümünde YFRÇ’ye üçüncü bölümünde ise BOBİ FRS'ye ilişsin literatür incelemesi yapılmıştır. Dördüncü ve son bölümde BOBİ FRS’ye ilişkin akademik yazın üzerine bir değerlendirmede bulunulmuş ve bu konuda araştırmaya yönelik öneriler verilmiştir. 


\section{YFRÇ ÜZERİNE LITTERATÜR İNCELEMESİ}

\subsection{YFRÇ Üzerine Literatür İncelemesinin Önemi}

YFRÇ, BOBİ FRS'nin temelini oluşturmaktadır. Bu bağlamda; geriye dönüp bakıldığında BOBİ FRS ortaya çıkarken akademik yazın ortamında YFRÇ’nin belirli bazı hususlar ve farklı bakış açıları çerçevesinde ele alındığı, değerlendirildiği ve tartışıldığı görülmektedir. Dolayısı ile YFRÇ ile ilgili literatür incelemesi bir finansal raporlama standardının oluşturulması sürecinde akademik yazında karşılaşılan farklı yaklaşımları ortaya koyduğu için önem arz etmektedir.

\subsection{YFRÇ Üzerine Literatür İncelemesine Genel Bakış}

YFRÇ ile ilgili olarak akademik yazında biri hariç hakemli dergilerde yayınlandığı tespit edilen ve bilinen 9 adet makale bulunmaktadır. Bu çerçevede, aşağıdaki hususlar tespit edilmiştir.

1. Makaleler, her biri ayrı bir dergi de olmak üzere aşağıdaki dergilerde yayınlanmıştı:

- Muhasebe Bilim Dünyası Dergisi,

- Muhasebe ve Vergi Uygulamaları Dergisi,

- Muhasebe ve Denetime Bakış Dergisi,

- Muhasebe ve Denetim Dünyası Dergisi ${ }^{1}$,

- Accounting in Europe Dergisi,

- Marmara Üniversitesi Öneri Dergisi,

- Pamukkale Üniversitesi Sosyal Bilimler Enstitüsü Dergisi,

- Vergi Sorunları Dergisi ve

- Uluslararası Sosyal Araştırmalar Dergisi

2. Makaleler, yazı dili açısından değerlendirilmiş sadece Öztürk (2017) tarafından yazılan makalenin İngilizce dilinde kaleme alındığı diğer makalelerin ise Türkçe olarak yazıldığı görülmüştür.

3. Makaleler araştırma türlerine göre sınıflandırılmış ve aşağıda Tablo 1'de görüleceği gibi yapılan yayınların yarıdan fazlasında (\%77) yazarların karşılaştırmalı bir yaklaşımla araşıtırma yapmayı tercih ettikleri gözlenmiştir.

Tablo 1: Makalelerin Türlerine Göre Sınıflandırılması

\begin{tabular}{|l|c|l|}
\hline \multicolumn{1}{|c|}{ Makaleler } & Sayı & \multicolumn{1}{|c|}{ Türü } \\
\hline $\begin{array}{l}\text { (Karataş, 2016; Kılınç, 2016; Özerhan, 2016; } \\
\text { Öztürk, 2017; Yünlü, 2016; Öztürk, 2017a) }\end{array}$ & 6 & Karş1laştırmalı araştırma \\
\hline (Ünkaya ve Dabbağoğlu, 2016) & 1 & $\begin{array}{l}\text { Karşılaştırmalı ve eleştirel } \\
\text { araştırma }\end{array}$ \\
\hline (Yılmaz ve diğerleri, 2016) & 1 & Ampirik araştırma \\
\hline (Kaya ve Türegün, 2017) & 1 & Betimleyici araştırma \\
\hline
\end{tabular}

4. Karşılaştırmalı bir yaklaşım sergileyen makaleler kendi içinde konularına göre ayrılmış ve aşağıda Tablo 2'de YFRÇ ile hangi hususu karşılaştırdıklarına göre

\footnotetext{
${ }^{1}$ Bu dergi, Kamu Gözetimi Kurumu Uzmanları Derneği’ne aittir. Derginin iç kapak sayfasında derginin hakemli olduğuna dair bir ibareye rastlanmamış olup, aynı sayfada dergi "mesleki ve akademik" olarak nitelendirildiğinden bu çalışmanın kapsamına alınmıştır.
} 
sınıflandırıldığında her bir makalenin bazı kesişmeler dışında özgün bir karşılaştırma sunduğu görülmüştür.

Tablo 2: Karşılaştırmalı Makaleler ve YFRÇ İlişkisi

\begin{tabular}{|c|c|}
\hline Karşılaştırmalı Makaleler & YFRÇ ile Karşılaştırma \\
\hline Yünlü (2016) & MSUGT ve TFRS ile Karşılaştırma \\
\hline Özerhan (2016) & $\begin{array}{c}\text { TFRS ile Ölçümleme Esasları } \\
\text { Açısından Karşılaştırma }\end{array}$ \\
\hline Öztürk (2017) & $\begin{array}{c}\text { Avrupa Birliği Yönergesi (2013/34)'den ve } \\
\text { TFRS'den Farkları Açısından Karş1laştırma }\end{array}$ \\
\hline Karataş (2016) & KOBİ TFRS ile Karşıllaştırma \\
\hline K1lıç (2016) & TFRS ile Yatırım Amaçlı Gayrimenkuller \\
& Açısından Karş1laştırma \\
\hline Öztürk (2017a) & $\begin{array}{c}\text { VUK ve TFRS ile Stok Maliyetlerinin Ölçüm ve } \\
\text { Muhasebeleştirmesi Açısından Karşılaştırma }\end{array}$ \\
\hline Ünkaya ve Dabbağoğlu (2016) & TFRS ile Hasılat ve Ticari Alacaklar \\
& Açısından Karşılaştırma \\
\hline
\end{tabular}

2.3. YFRÇ Üzerine Literatür İncelemesi Kapsamındaki Makalelerin İçerik Açısından Değerlendirilmesi

\subsubsection{Karşılaştırmalı Araştırma Yöntemini Kullanan Makalelerin İçerik Açısından Değerlendirilmesi}

$\mathrm{Bu}$ kapsamda yer alan makalelerden Yünlü (2016) çalışmasında öncelikle YFRÇ'ye etki eden Avrupa Birliği'nin 2013/34 no'lu direktifinden, KGK'nın ilgili direktif ile uyumlu bir finansal raporlama standard hazırlama hedefinden ve de YFRÇ’nin temel özelliklerinden söz etmiştir. Daha sonra YFRÇ'nin temel hükümlerini Muhasebe Sistemi Uygulama Genel Tebliğleri (MSUGT) ve TFRS'nin temel hükümleri ile karşılaştırmış ve farklılıkları ele almıştır.

Özerhan (2016) çalışmasında YFRÇ’de yer alan ölçümleme esaslarını TFRS kapsamındaki ölçümleme esasları ile karşılaştırmıştır. Bu doğrultuda, yazar yaptığ analiz sonucunda YFRÇ'de TFRS'ye yakınsama sağlanan muhasebe politikaları olduğu kadar yakınsama sağlanamayıp Türkiye'deki Tekdüzen Muhasebe Sistemine ve vergi mevzuatına uygun ölçümleme esaslarına bağlı kalınan hususlar da olduğunu tespit etmiştir. Bu çalışma, YFRÇ’nin uluslararası uygulamaları dikkate aldığı kadar bazı muhasebe politikalarında da tutucu bir yaklaşım sergilediğini göstermişstir.

Öztürk (2017) ulusal muhasebe kurallarının tamamlanmasında UFRS'nin halihazırdaki rolünü ve statüsünü Türkiye açısından ele almıştır. Bu doğrultuda, yazar Türkiye'de finansal raporlamanın çerçevesini çizerek bağımsız denetime tabi olup kamuya hesap verme yükümlülüğü bulunmayan işletmeler açısından yapılmakta olan finansal raporlama çalışmasını YFRÇ perspektifinden incelemiştir. Bu çerçevede, çalışmada YFRÇ’nin gerek dayandığı Avrupa Birliği Yönergesi (2013/34) ve gerekse UFRS açısından farkları karşılaştırmalı olarak temel noktalarda ortaya konmuştur. $\mathrm{Bu}$ çalışmanın, YFRÇ'yi anlatırken Türkiye'nin küçük ve orta büyüklükteki işletmeler için finansal raporlama açısından izlemekte olduğu yol hakkında uluslararası çevreleri bilgilendirdiği görülmüştür. 
Karataş (2016)'ya ait olan çalışmada YFRÇ muhasebe politikaları Küçük ve Orta Büyüklükteki İşletmeler için Türkiye Finansal Raporlama Standardı (KOBİ TFRS) hükümleri ile karşılaştırılmıştır. Bu bağlamda, farklar ve benzerlikler ortaya konmuştur. Hatırlatmak gerekirse KOBİ TFRS 2009 yılında Uluslararası Muhasebe Standartları Kurulu (UMSK - IASB) tarafından yayınlanan Küçük ve Orta Büyüklükteki İşletmeler için Uluslararası Finansal Raporlama Standardının (KOBI'ler için UFRS - IFRS for SMEs) 2011 yılında Türkçeye çevrilerek eski Türkiye Muhasebe Standartları Kurulu tarafından Türkiye'de yayınlanmış ve mevzuata kazandırılmış şeklidir.

Kılınç (2016) çalışmasının başlığında TFRS ve YFRÇ açısından karşılaştırmalı olarak ele aldığını belirttiği yatırım amaçlı gayrimenkullere ilişkin muhasebe politikalarını çalışmasının metin kısmında birbirinden bağımsız olarak ele almıştır. Ancak, yazar çalışmanın sonucunda yatırım amaçlı gayrimenkullere ilişkin muhasebe politikalarının YFRÇ'de TFRS'ye oranla kullanımı daha kolay olan ve daha dar kapsamlı muhasebe politikaları olduğu sonucuna vardığını belirtmiştir. Bu çalışmanın özelliği yatırım amaçlı gayrimenkullere ilişkin muhasebe kayıtlarının nasıl olacağına ilişkin örnek uygulamalara yer verilmiş olmasıdır.

Öztürk (2017a) tarafından kaleme alınan çalışmada Vergi Usul Kanunu (VUK), TFRS ve YFRÇ’nin stokların ölçme ve muhasebeleştirilmesine ilişsin hükümlerini karşılaştırılmıştır. Yazar çalışmasında stokların ölçme ve muhasebeleştirilmesine yönelik olarak VUK ve TFRS hükümleri arasında belirgin farklar olduğunu ifade etmiştir. Buna ek olarak YFRÇ metninde de VUK ve TFRS'ye yakınsayan bazı uygulamalar olduğunu belirtmiştir. Yazar çalışmasını hazırladığı karşılaştırmalı tablolarla ve stoklara ilişkin üç mevzuatı muhasebe kayıtlarına dönüştüren örnek uygulamalarla desteklemiştir.

\subsubsection{Karşılaştırmalı ve Eleştirel Araştırma Yöntemlerini Kullanan Makalenin İçerik Açısından Değerlendirilmesi}

Ünkaya ve Dabbağoğlu (2016) tarafından yayınlanan çalışmada YFRÇ'de hasılat unsuru olarak satış gelirinin vadeli işlem tutarı, bu tür işlemlerden kaynaklanan alacağın ise nominal faiz yöntemi ile reeskont uygulamasına tabi tutularak bugünkü değeri üzerinden raporlanmasına ilişkin öneri eleştirel bir yaklaşımla TFRS ile karşılaştırmalı olarak ele alınmıştır. Bu doğrultuda, taslakta yapılan öneri, hasılat, ticari alacak ve nitelikli finansal bilgi kavramları çerçevesinde açıklanarak eleştirilmiş ve satış gelirinin peşin işlem tutarı üzerinden raporlanması, vade farkı tutarının faiz geliri olarak tanımlanması ve dolayısıyla işlemde uygulanan vade farkı oranı üzerinden efektif faiz yöntemi ile itfa edilerek raporlanması savunulmuştur ki bu hususlar karşılaştırılabilirlik ve sosyal sorumluluk kavramları ile de ilişkilendirilmiştir.

\subsubsection{Ampirik Araştırma Yöntemini Kullanan Makalenin İçerik Açısından Değerlendirilmesi}

Yılmaz ve diğerleri (2016) tarafından kaleme alınan makalede YFRÇ taslağına ilişskin olarak meslek mensuplarının görüşlerini alabilmek için "YFRÇ Taslağının Muhasebe Meslek Mensupları Açısından Değerlendirilmesi” ne yönelik bir uygulama yapılmıştır. Ankara ilinde çalışan Serbest Muhasebeci Mali Müşavir ve Yeminli Mali Müşavirler araştırmanın örneklemini oluşturmuş olup meslek mensuplarının görüşlerini alabilmek için 5'li likert tipi olarak hazırlanan anket iki kısımdan oluşmuştur. 
Birinci kısımda meslek mensuplarının görüşleri 7 soruda incelenmiştir. $\mathrm{Bu}$ sorular; (1) YFRÇ'nin anlatım dilinin açık ve sade olup olmadığına, (2) YFRÇ ile gerçeğe uygun finansal tablolar oluşturulup oluşturulamayacağına, (3) YFRÇ’nin küçük ve orta büyüklükteki işletmelerin finansal raporlama yükümlülüklerini hafifletip hafifletmeyeceğine, (4) YFRÇ ile Avrupa Birliği direktiflerine uyum sağlanıp sağlanmayacağına, (5) YFRÇ'nin finansal tablo kullanıcılarının bilgi ihtiyaçlarını karşılayabilecek düzeyde olup olmadığına, (6) YFRÇ'de finansal riskten korunma muhasebesine yer verilmesinin gerekip gerekmediğine ve (7) YFRÇ'de maddi duran varlıkların amortisman yöntemlerinin belirlenip belirlenmemesine ilişkin hususları içermiştir.

İkinci kısımda ise meslek mensuplarının yapılması öngörülen değişikliklere ilişkin görüşleri 10 soruda ele alınmıştır. Bu sorular; (1) bilançoda stoklar, maddi ve maddi olmayan duran varlıklar ile diğer alacak ve borçların daha ayrıntılı olarak sunulması isteğinin kaliteli ve anlaşılabilir finansal tabloların hazırlanmasını sağlayıp sağlamayacağına, (2) nakit akış tablosunun zorunlu tutulmamasının finansal tablo kullanıcılarının bilgi gereksinimlerini karşılamalarına katkı sağlayıp sağlamayacağına, (3) Avrupa Birliği muhasebe direktiflerindeki genel raporlama ilkelerinin esas alınmasının gerçeğe uygun sunum amacına yaklaştırıp yaklaştırmadığına, (4) genel üretim giderlerinin stoklara yüklenmesinde normal maliyet veya tam maliyet yönteminin kullanılması tercihinin doğru bir uygulama olup olmadığına, (5) ticari ve diğer alacakların finansal durum tablosunda itfa edilmiş değerleri ile değil mukayyet değerleri ile gösterilip dönem sonlarında reeskonta tabi tutulmasının uygun olup olmadığına, (6) iştiraklerin büyük işletmelerde özkaynak yöntemi ile diğer işletmelerde maliyet yöntemi ile değerlenmesinin uygun olup olmadığına, (7) borçlanma maliyetlerinin aktifleştirilmesinde varlık tanımının yapılmasının gerekip gerekmediğine, (8) konsolide finansal tabloların sadece büyük işletmeler tarafından değil tüm işletmeler tarafindan yerine getirilip getirilmemesine, (9) ertelenmiş verginin sadece büyük işletmeler için değil tüm işletmeler için zorunlu olup olmamasına ve (10) konsolide finansal tablo hazırlayan işletmelerin bireysel finansal tablolarında da dipnot uygulamasının zorunlu tutulup tutulmaması ilişkin hususları kapsamıştır.

Gerek birinci kısımdaki gerekse ikinci kısımdaki sorular, muhasebe meslek mensuplarının mesleki tecrübesi, mesleki unvanı ve eğitim durumları da dikkate alınarak analiz edilmiştir. Bu çerçevede, meslek mensuplarının YFRÇ taslağına ilişkin olumlu bakış açılarının mesleki tecrübeye, mesleki unvana ve eğitim durumuna bakılmaksızın geçerli olduğu ifade edilmiştir.

Çalışmanın sonucunda YFRÇ’nin başarı ile uygulanması için mevzuatın uyumlu hale getirilmesinin yanında özellikle meslek içi eğitimin altı çizilmiştir.

\subsubsection{Betimleyici Araştırma Yöntemini Kullanan Makalenin İçerik Açısından Değerlendirilmesi}

Kaya ve Türegün (2017) çalışmalarında ilk olarak KOBİ kavramını dünya KOBİ tanımları ve ölçümleri çerçevesinde incelemiş ve KOBİ'lerin dünya ve Türkiye ekonomisindeki yerine yer vermişlerdir. Daha sonra, ileride sermaye piyasalarına dahil olmay1 planlayan KOBI'lerin UFRS'ye geçişini kolaylaştıracak bir standart gereksiniminin ortaya çıktığına değinerek KOBI'ler için UFRS çerçevesinde Amerika Birleşik Devletleri, Avrupa ülkeleri ve diğer ülkeler nezdinde bir durum değerlendirmesi yapılmıştır. Çalışmanın son kısmında ise KOBİ'ler için Finansal 
Raporlama konusu Türkiye açısından ele alınarak Türkiye'de finansal raporlamanın çerçevesi çizilmiş ve KOBI'ler için finansal raporlama YFRÇ dikkate alınarak değerlendirilmiştir.

\subsection{YFRÇ Üzerine Literatür İncelemesi Kapsamındaki Makalelerin Aldıkları Atıflar Açısından Değerlendirilmesi}

YFRÇ ile ilgili olarak burada incelenen makalelerin, daha sonra yazılmış bazı makalelere alt yapı oluşturduğu tespit edilmiştir. $\mathrm{Bu}$ çerçevede, literatür incelemesi açısından bu makalelerin 2017 yılı sonu itibariyle aldıkları atıflar bir veri olarak kabul edilmiştir.

Dolayısıyla, YFRÇ ile ilgili olarak burada incelenen makalelere daha sonra yazılmış makaleler tarafından verilen atıflar Google Scholar ile sınırlı olmak üzere tespit edildikten sonra aşağıda Tablo 3 'de raporlanmıştır.

Tablo 3: YFRÇ Üzerine Literatür İncelemesi ve Alınan Atıflar

\begin{tabular}{|c|c|}
\hline Makaleler & Aldıkları Atıflar \\
\hline $\begin{array}{l}\text { Yünlü, M. (2016). Bağımsı Denetime } \\
\text { Tabi Olup TMS/TFRS'leri Uygulama } \\
\text { Kapsamında Olmayan Issletmeler İçin } \\
\text { Finansal Raporlama Standartları. } \\
\text { Muhasebe ve Denetim Dünyasl, 1(1), } \\
\text { 23-42. }\end{array}$ & $\begin{array}{l}\text { 1.Öztürk, E. (2017). Finansal Varlıkların Ölçme ve } \\
\text { Muhasebeleştirme Esaslarının Büyük ve Orta } \\
\text { Boy İşletmeler Iç̧in Finansal Raporlama } \\
\text { Standardı ve Türkiye Finansal Raporlama } \\
\text { Standartları Açısından Karşılaştırılması. İşletme } \\
\text { Araştırmaları Dergisi, 9(3), 594-617. } \\
\text { 2. Yylmaz, Z. (2017). TR90 Bölgesindeki SMMM } \\
\text { Oda Başkanlarının BOBİ FRS Konusundaki } \\
\text { Görüşleri. Journal of Social and Humanities } \\
\text { Sciences Research. Vol:4/15:1866-1880. }\end{array}$ \\
\hline 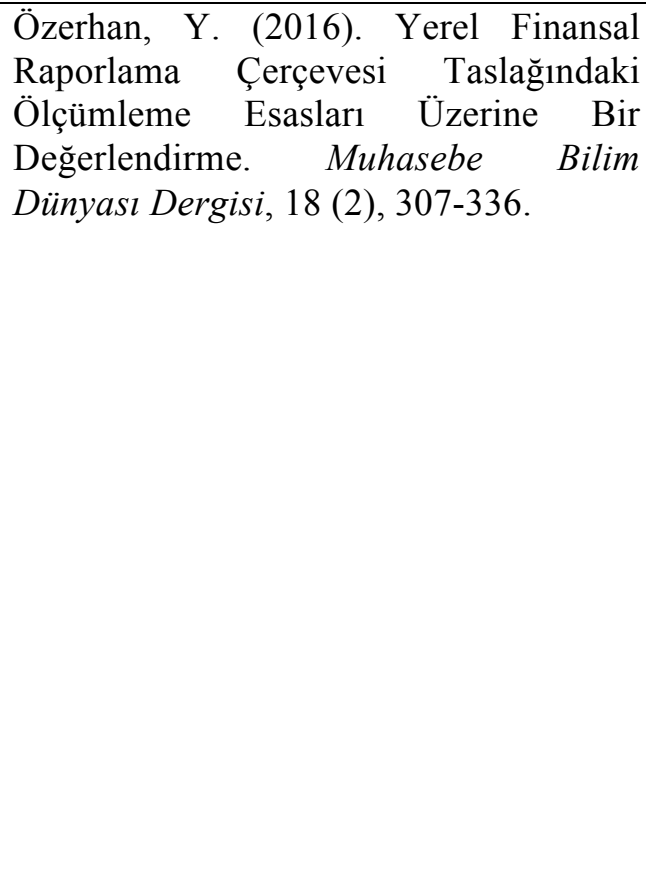 & $\begin{array}{l}\text { 1.Öztürk, C. (2017). The role and current status of } \\
\text { IFRS in the completion of national accounting } \\
\text { rules-Evidence from Turkey. Accounting in } \\
\text { Europe, 14(1-2), 226-234. } \\
\text { 2.Öztürk, E. (2017). Finansal Varlıkların Ölçme ve } \\
\text { Muhasebeleştirme Esaslarının Büyük ve Orta } \\
\text { Boy İşletmeler İçin Finansal Raporlama } \\
\text { Standard ve Türkiye Finansal Raporlama } \\
\text { Standartları Açısından Karş1laştırılması. İşletme } \\
\text { Araştırmaları Dergisi, 9(3), 594-617. } \\
\text { 3.Öztürk, E. (2017). Stok Maliyetlerinin Ölçüm ve } \\
\text { Muhasebeleştirme Esaslarının VUK, TMS/TFRS } \\
\text { VE YFRÇ Taslağ1 Açısından Karş1laştırılmas1. } \\
\text { Pamukkale Üniversitesi Sosyal Bilimler Enstitüsü } \\
\text { Dergisi, (28): 141-157. } \\
\text { 4.Dinç, E., \& Atasel, O. Y. (2016). Türkiye'deki } \\
\text { Muhasebe Anlayışının Gelişim Süreci ve Mevcut } \\
\text { Durumun İncelenmesi. Karadeniz Teknik } \\
\text { Üniversitesi Sosyal Bilimler Enstitüsü Dergisi, } \\
\text { (12), 267-283. }\end{array}$ \\
\hline $\begin{array}{l}\text { Öztürk, C. (2017). The role and current } \\
\text { status of IFRS in the completion of } \\
\text { national accounting rules-Evidence } \\
\text { from Turkey. Accounting in Europe, } \\
\text { 14(1-2), 226-234. }\end{array}$ & $\begin{array}{l}\text { 1. André, P. (2017). The role and current status of } \\
\text { IFRS in the completion of national accounting } \\
\text { rules-evidence from European countries. } \\
\text { Accounting in Europe, 14(1-2), 1-12. } \\
\text { 2.K1liç, M., \& Uyar, A. (2017). Adoption Process }\end{array}$ \\
\hline
\end{tabular}




\begin{tabular}{|c|c|}
\hline & $\begin{array}{l}\text { of IFRS for SMEs in Turkey: Insights from } \\
\text { Academics and Accountants. Journal of } \\
\text { Accounting and Management Information } \\
\text { Systems, 16(2), 313-339. } \\
\text { 3. Temiza, H., \& Güleç, Ö. F. Mandatory adoption } \\
\text { of IFRS in emerging markets: the case of Turkey. } \\
\text { Journal of Accounting and Management } \\
\text { Information Systems, 16(4), 560-580 }\end{array}$ \\
\hline $\begin{array}{l}\text { Karataş, M. (2016). Yerel Finansal } \\
\text { Raporlama Çerçevesi Taslağı ve KOBİ } \\
\text { TFRS İle Karşılaştırılması. } \text { Vergi } \\
\text { Sorunları Dergisi, 39(328), 73. }\end{array}$ & $\begin{array}{l}\text { 1.Kaya, C. T., \& Türegün, N. (2016). Dünyada } \\
\text { KOBİ Finansal Raporlama Uygulamaları ve } \\
\text { Türkiye için Çıarımlar: Yerel Finansal } \\
\text { Raporlama Çerçevesine Bakış. Muhasebe ve } \\
\text { Denetime Bakıs, 16(50), 97. } \\
\text { 2.Özerhan, Y. (2016). Yerel Finansal Raporlama } \\
\text { Çerçevesi Taslağındaki Ölçümleme Esasları } \\
\text { Üzerine Bir Değerlendirme, Muhasebe Bilim } \\
\text { Dünyası Dergisi, 18 (2), 307-336. }\end{array}$ \\
\hline $\begin{array}{l}\text { Öztürk, E. (2017a). Stok Maliyetlerinin } \\
\text { Ölçüm ve Muhasebeleştirme Esaslarının } \\
\text { VUK, TMS/TFRS VE YFRÇ Taslağ1 } \\
\text { Açısından Karş1laştırılması. Pamukkale } \\
\text { Üniversitesi Sosyal Bilimler Enstitüsü } \\
\text { Dergisi, (28): 141-157. }\end{array}$ & Tespit edilememiştir. \\
\hline 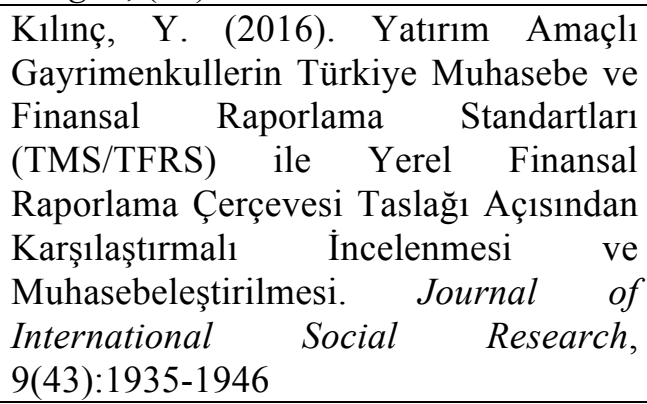 & Tespit edilememiştir. \\
\hline $\begin{array}{l}\text { Ünkaya, G., \& Dabbağoğlu, K. (2016). } \\
\text { Yerel Finansal Raporlama Çerçevesi } \\
\text { Taslağında Önerilen Satış Geliri ve } \\
\text { Ticari Alacak Muhasebesi Üzerine Bir } \\
\text { Eleştiri. Marmara Unniversitesi Öneri } \\
\text { Dergisi, 12(46), 121-136. }\end{array}$ & Tespit edilememiştir. \\
\hline $\begin{array}{l}\text { Y1lmaz, B., Dölen, T., \& Atik, M. } \\
\text { (2016). Yerel Finansal Raporlama } \\
\text { Çerçevesinin } \quad \text { Muhaseber Meslek } \\
\text { Mensupları } \\
\text { Değerlendirilmesi: Ankara İli Meslek } \\
\text { Mensupları Uygulamas1. Muhasebe ve } \\
\text { Vergi Uygulamalari Dergisi (MUVU), } \\
\text { 9(3): 297-326. }\end{array}$ & Tespit edilememiştir. \\
\hline $\begin{array}{l}\text { Kaya, C. T., \& Türegün, N. (2016). } \\
\text { Dünyada KOBİ Finansal Raporlama } \\
\text { Uygulamaları ve Türkiye için } \\
\text { Çıkarımlar: Yerel Finansal Raporlama } \\
\text { Çerçevesine Bakış. Muhasebe ve } \\
\text { Denetime Bakış, 16(50), } 97 .\end{array}$ & Tespit edilememiştir. \\
\hline
\end{tabular}




\section{BOBİ FRS ÜZERİNE LITTERATÜR İNCELEMESİ}

\subsection{BOBİ FRS Üzerine Literatür İncelemesinin Önemi}

Yayınlandığından beri BOBİ FRS ile ilgili çeşitli makalelerin kaleme alındığ 1 görülmüştür. Ancak, yapılan yayın sayısı sınırlıdır. Bu doğrultuda, BOBİ FRS ile ilgili olarak farklı konular ve bakış açıları ile yazılacak makalelere yön vermek amacıyla bu bölümdeki literatür incelemesi 2017 yılı sonu itibariyle basılmış makaleleri inceleyerek akademik yazına BOBİ FRS ile ilgili olarak katkı vermesi açısından önemlidir.

\subsection{BOBİ FRS Üzerine Literatür İncelemesine Genel Bakış}

BOBİ FRS ile ilgili olarak akademik yazında tamamı hakemli dergilerde yayınlandığ 1 tespit edilen ve bilinen 6 adet makale bulunmaktadır. Bu çerçevede, aşağıdaki hususlar tespit edilmiştir.

1. Makaleler, Tablo 4'de görüldüğü gibi aşağıdaki dergilerde yayınlanmıştır:

Tablo 4: 2017 yılı Sonu İtibariyle BOBİ FRS Konulu Makale Basmış Dergiler

\begin{tabular}{|l|c|}
\hline \multicolumn{1}{|c|}{ Dergiler } & Makale Sayıları \\
\hline$\bullet$ Muhasebe ve Finansman Dergisi & 1 \\
\hline$\bullet$ Journal of Social and Humanities Sciences Research & 1 \\
\hline$\bullet$ Finans, Ekonomi ve Sosyal Araştırmalar Dergisi & 2 \\
\hline$\bullet$ İşetme Araştırmaları Dergisi & 2 \\
\hline
\end{tabular}

2. Makaleler, yazı dili açısından değerlendirilmiş ve tamamının Türkçe olduğu görülmüştür.

3. Makaleler araştırma türlerine göre sınıflandırılmış ve aşağıda Tablo 5'de görüleceği gibi yapılan yayınların neredeyse tamamında (\%83) yazarların karşılaştırmalı bir yaklaşımla araştırma yapmayı tercih ettikleri gözlemlenmiştir.

Tablo 5: Makalelerin Türlerine Göre Sınıflandırılması

\begin{tabular}{|l|c|l|}
\hline \multicolumn{1}{|c|}{ Makaleler } & Sayı & \multicolumn{1}{|c|}{ Türü } \\
\hline $\begin{array}{l}\text { (Gençoğlu, 2017; Ataman ve Cavlak, } \\
\text { 2017; Öztürk 2017b; Doğan 2017) }\end{array}$ & 4 & Karş1laştırmalı araştırma \\
\hline (Gökçen ve Öztürk, 2017) & 1 & $\begin{array}{l}\text { Karş1laştırmalı ve eleştirel } \\
\text { araştırma }\end{array}$ \\
\hline (Yılmaz, 2017) & 1 & Nitel araştırma \\
\hline
\end{tabular}

4. Karşılaştırmalı bir yaklaşım sergileyen makaleler kendi içinde konularına göre ayrılmış ve aşağıda Tablo 6' da BOBİ FRS ile hangi hususu karşılaştırdıklarına göre sınıflandırıldığında her bir makalenin bazı kesişmeler dışında özgün bir karşılaştırma sunduğu görülmüştür.

Tablo 6: Karşılaştırmalı Makaleler ve BOBİ FRS İlişkisi

\begin{tabular}{|c|c|}
\hline Karşılaştırmalı Makaleler & BOBİ FRS ile Karşılaştırma \\
\hline Gençoğlu (2017) & TFRS ile Karşılaştırma \\
\hline Doğan $(2017)$ & TFRS ile Karş1laştırma \\
\hline Ataman ve Cavlak (2017) & TFRS ile Karş1laştırma \\
\hline Öztürk (2017b) & $\begin{array}{c}\text { TFRS ile Finansal Varlıkların Ölçme ve } \\
\text { Muhasebeleştirme Esasları Açısından Karşılaştırma }\end{array}$ \\
\hline Gökçen ve Öztürk (2017) & $\begin{array}{c}\text { TFRS ile Tam Maliyet ve Normal Maliyet } \\
\text { Açısından Karş1laştırma }\end{array}$ \\
\hline
\end{tabular}




\subsection{BOBİ FRS Üzerine Literatür İncelemesi Kapsamındaki Makalelerin İçerik Açısından Değerlendirilmesi}

\subsubsection{Karşılaştırmalı Araştırma Yöntemini Kullanan Makalelerin İçerik Açısından Değerlendirilmesi}

Karşılaştırmalı araştırma yöntemini kullanan makalelerden üç tanesi BOBİ FRS'ye ait muhasebe politikaları ile TFRS muhasebe politikalarını birbirleri karşılaştırmaktadır (Gençoğlu, 2017; Doğan, 2017; Ataman ve Cavlak, 2017). Dolayıs1 ile bu çalışmaların konuları ortak olduğundan bu makaleler, yazarların konuya kattıkları kendi bakış açıları ve konuyu işleyiş şekilleri çerçevesinde farklılık göstermektedir.

Karşılaştırmalı araştırma yöntemini kullanarak BOBI FRS'ye ait muhasebe politikaları ile TFRS muhasebe politikalarını birbirleri ile karşılaştıran makalelerden Gençoğlu (2017) çalışmasında BOBİ FRS kapsamında yer alan, bazı özellikli sektörler ve durumlar için kullanılanlar hariç olmak üzere tüm işletmelerin kullanacağı BOBİ FRS bölümlerini seçerek TFRS hükümleri ile temel konularda karşılaştırma yapmıştır. Yazar, karşılaştırma yapmak amacıyla araştırmasını (1) Finansal Raporlama, (2) Finansal Varlık ve Yükümlülükler, (3) Hasılatın Raporlanması, (4) Stok ve Satış Maliyetlerinin Raporlanması, (5) Maddi Duran Varlıklar, (6) Maddi Olmayan Duran Varlıklar, (7) Varlıklarda Değer Düşüklüğü ve (8) Yatırım Amaçlı Gayrimenkuller olmak üzere 8 konu başlığına ayırmıştır.

Bu doğrultuda; her bir konu başlığı altında o konu ile ilgili BOBİ FRS bölümlerini bir araya getirerek toplamda BOBİ FRS'ye ait 15 bölüme ilişkin temel muhasebe politikaları incelenmiştir. İncelenen bölümler; Bölüm 1 Kavramsal Çerçeve ve Finansal Tablolar, Bölüm 3 Muhasebe Politikaları, Tahminler ve Yanlışlıklar, Bölüm 4 Bilanço Tarihinden Sonraki Olaylar, Bölüm 5 Hasılat, Bölüm 6 Stoklar, Bölüm 9 Finansal Araçlar ve Özkaynaklar, Bölüm 10 İştiraklerdeki Yatırımlar, Bölüm 11 Müşterek Girişimlerdeki Yatırımlar, Bölüm 12 Maddi Duran Varlıklar, Bölüm 13 Yatırım Amaçlı Gayrimenkuller, Bölüm 18 Varlıklarda Değer Düşüklüğü, Bölüm 19 Karşılıklar, Şarta Bağlı Yükümlülükler ve Şarta Bağlı Varlıklar, Bölüm 21 İş Birleşmesi, Bölüm 22 Konsolide Finansal Tablolar ve Bölüm 23 Gelir Üzerinden Alınan Vergiler'dir.

Çalışmanın sonucunda (1) BOBİ FRS'deki muhasebe politikalarının TFRS'deki muhasebe politikaları ile büyük ölçüde uyumlu olduğu, (2) BOBİ FRS kapsamına alınmayan standartlar, TFRS'deki hükümlere kıyasla yapılan sadeleştirmeler ve kapsamlı kar kavramının kullanılmaması nedeniyle finansal durum tablosu, kar zarar tablosu ve özkaynak değişim tablosu formatında değişiklikler ortaya çıtı̆̆ı ve (3) büyük işletmeler tarafından finansal tablo kalemlerinin ölçümünde gerçeğe uygun değer kavramının kullanıldığı belirtilmiştir.

BOBI FRS'ye ait muhasebe politikaları ile TFRS hükümlerini birbiri ile karşılaştıran diğer bir çalışma Doğan (2017) tarafından kaleme alınmıştır. Yazar, çalışmasını geliştirirken konuyu (1) BOBİ FRS'nin Hazırlanma Gerekçesi ve Aşamaları, (2) BOBİ FRS'nin Genel Özellikleri ve (3) BOBİ FRS ile TFRS Karşılaştırması başlıkları altında kurgulamıştır. Bu çalışmada BOBİ FRS'ye ait toplam 27 bölümü kapsayan bir karşılaştırma yapılarak her bölümde BOBİ FRS'nin TFRS ile uyumlu ve farklı olan yönleri ifade edilmiştir.

Çalışmanın sonucunda (1) BOBİ FRS'nin TFRS hükümleri ile karşılaştırıldığında, bazı yönleriyle benzerlik göstermekle birlikte, genel olarak daha basitleştirilmiş 
hükümler içerdiği ve (2) TFRS'lerde gerçeğe uygun değer kullanımı yaygın olmakla birlikte, BOBİ FRS'deki muhasebe uygulamalarında kolaylık sağlanması amaciyla maliyet bedelinin esas alındığ 1 sonucuna varılmıştır.

BOBİ FRS ve UFRS hükümlerini karşılaştırarak sunan son çalışma ise Ataman ve Cavlak (2017) tarafından hazırlanmıştır. Çalışma (1) Büyük ve Orta Boy İşletmeler için Finansal Raporlama Standardı ve (2) BOBİ FRS ve TFRS Karşılaştırması ana başlıkları altında şekillendirilmiştir. Ancak, ikinci ana başlık da kendi içinde üç alt başlığa bölünerek tespit ve değerlendirmeler (a) BOBİ FRS \& TFRS: Uygulayacak Olan İşletmeler; (b) BOBİ FRS \& TFRS: Bölüm ve Standart Karşılaştırması ve (c) BOBİ FRS \& TFRS: Değerlendirme başlıkları çerçevesinde yapılmıştır. Bu makalede BOBİ FRS'deki 27 bölüm dikkate alınmıştır. Bu araştırmada yapılan üç değerlendirme göze çarpmaktadır:

(1) Yazarlar, TFRS'de bulunan 44 muhasebe politikasının \%70,5'inin (31'i) BOBİ FRS' deki bölümlerde yer almışken; \%29,5'inin (13'ü) ise BOBİ FRS' de kendine yer bulamadığını belirtmiştir.

(2) Yazarlar, (a) BOBİ FRS ile ilgili olan muhasebe politikalarının TFRS kitapçı̆̆ındaki toplam sayfa sayısı 703 iken bu sayfa sayısının BOBİ FRS'deki tüm bölümlere 195 sayfa olarak yansıdığını, (b) bir başka deyişle TFRS'de BOBİ FRS ile ilgili olan 31 muhasebe politikasının sayfa sayısının yaklaşık \%28'inin BOBİ FRS'deki 27 bölümü oluşturduğunu ve (c) bu bilginin KGK tarafından BOBİ FRS ile ilgili yapıldığı ifade edilen sadeleştirmenin de bir kanıtı olarak görülebileceğini ifade etmişlerdir.

(3) Yazarlar, BOBİ FRS bölümlerinin TFRS ile uyumluluk düzeylerini bölüm sayıları çerçevesinde ele almıştır. $\mathrm{Bu}$ amaçla, BOBİ FRS bölümlerinin TFRS'ye uyumunu tespit etmek üzere yüksek, orta ve düşük seviyede uyumluluk göstergeleri belirlemişlerdir.

Bu göstergelere göre yazarlar (a) yüksek uyum için ilgili BOBİ FRS bölümü ile TFRS arasında en fazla bir fark olmasını, (b) orta uyum olması için BOBİ FRS bölümü ile TFRS arasında en az iki veya daha fazla ve de (c) düşük uyum olması için BOBİ FRS bölümü ile TFRS arasında birçok konuda farklılık olmasını beklemişlerdir. $\mathrm{Bu}$ doğrultuda, BOBİ FRS'deki 17 bölümün TFRS ile yüksek uyumlu, 9 bölümün orta derecede uyumlu ve de 1 bölümün düşük seviyede uyumlu olduğu sonucuna varmışlardır.

Bu üç makale (Gençoğlu, 2017; Doğan, 2017; Ataman ve Cavlak, 2017) BOBİ FRS hükümlerinin TFRS hükümleri ile karşılaştırılması noktasında değerlendirildiğinde her bir makalenin literatüre ayrı bir katkı sunduğu ve bu bağlamda burada referans verilen sırayla okunmaları durumunda birbirini tamamlayıcı nitelikte olduğu tespit edilmişstir.

Bu bölümde değinilecek son makale ise Öztürk (2017b) tarafından hazırlanmıştır. Öztürk (2017b) çalışmasında finansal varlıklara ilişkin ölçme ve muhasebeleştirme esaslarını BOBİ FRS ve TFRS çerçevesinde karşılaştırmalı olarak incelemiştir. Yazar, makalesini (1) BOBİ FRS'ye Yönelik Genel Bakış ve (2) Finansal Varlıklarda Sınıflandırılma, Ölçüm ve Muhasebeleştirilme Esaslarının TFRS ve BOBİ FRS Açısından İncelenmesi olmak üzere iki ana başlık altında şekillendirmiştir. 
İlk ana başlık kendi içerisinde (a) BOBİ FRS Uygulamak Zorunda Olan Şirketlerin Kapsamı ve (b) Finansal Varlıklar ile İlgili Olarak BOBİ FRS’nin Öne Çıkan Özellikleri olmak üzere iki alt başlığa ayrılmıştır.

Diğer taraftan, ikinci ana başlık kapsamındaki konular ise (a) Finansal Varlıkların TFRS ve BOBİ FRS Açısından Sınıflandırılması, (b) Finansal Varlıkların TFRS 9 Finansal Araçlar Standardı ve BOBİ FRS Standardı Açısından Ölçümü ve Muhasebeleştirilmesi ve (c) TFRS 9 Standardı ve BOBİ FRS Standardına Göre Finansal Varlıklara İlişkin Muhasebe Uygulamaları olmak üzere üç alt başlıkta irdelenmiştir.

Çalışmanın sonucunda finansal varlıklara ilişkin olarak TFRS hükümleri ile BOBİ FRS hükümleri arasında yakınsama olduğu ancak tam uyumun söz konusu olmadığı sonucuna varılmıştır.

Öztürk (2017b)'nin çalışması, karşılaştırmaları sadece TFRS ve BOBİ FRS metinleri üzerinden yapmakla bırakmayıp karşılaştırma ortamını örnek uygulamalara taşımıştır. Dolayısı ile TFRS ve BOBİ FRS'de finansal varlıklara ilişkin hükümlerin nasıl yevmiye kaydına dönüştürülebileceği vakalar yardımıyla incelenerek standart hükümleri somut bir hale dönüştürülmüştür.

\subsubsection{Karşılaştırmalı ve Eleştirel Araştırma Yöntemlerini Kullanan Makalenin İçerik Açısından Değerlendirilmesi}

Gökçen ve Öztürk (2017) çalışmalarında stoklara ilişkin olarak tam maliyet ve normal maliyet yöntemlerini TFRS ve BOBİ FRS hükümleri çerçevesinde öncelikle karşılaştırmalı olarak ele almıştır. Makale, (1) TFRS ve BOBİ FRS'de Önerilen Maliyet Yöntemlerinin Gelişimi ve Maliyet Muhasebesi Sistemleri Üzerindeki Etkileri ve (2) TFRS ve BOBİ FRS'deki Düzenlemelerin Değerlendirilmesi olmak üzere iki ana başlık çerçevesinde şekillendirilmiştir.

Birinci ana başlık altında ele alınan konular; maliyet ölçümleme sisteminin gelişimi çerçevesinde kısmi maliyet yöntemlerinin ortaya çıkışı ve normal maliyet yöntemlerinin benimsenmesi, kapasite farkı kavramının ortaya çıkışı ve maliyetlerin normal kapasite ölçüsü ile ölçümlenmesi konuları ile maliyet kayıt sisteminin gelişimi çerçevesinde tam maliyet ve normal maliyet yöntemine göre kayıt sistemini kapsamaktadır. Ayrıca, TFRS ve BOBİ FRS'de önerilen tam maliyet ve normal maliyet yöntemlerinin fayda ve sakıncalarına da değinilmiştir. Bu başlık altında özellikle tam maliyetle birlikte normal maliyet yönteminin teorik alt yapısının da ortaya konulduğu görülmüştür.

İkinci ana başlık altında ise TFRS'deki stoklar standardında normal maliyete ilişskin muhasebe politikaları BOBİ FRS'deki normal maliyet ve tam maliyete ilişkin düzenlemelerle karşılaştırılmıştır. Yazarlar, normal maliyet yöntemine göre düşük kapasite ya da atıl kapasite nedeniyle dağıtılamayan genel üretim giderlerinin TFRS'de belirli bir hesap kalemi belirtilmeden "dönem gideri" olarak kaydedilerek kar veya zararla ilişkilendirilmesi karşısında bu giderlerin BOBİ FRS'de "satışların maliyeti" kalemi içine dahil edilmesi hususunu eleştirel bir yaklaşımla irdelemişlerdir.

BOBİ FRS'yi uygulama yapan bir işletmenin normal maliyet yöntemine göre raporlama yapması durumunda kullanılmayan kapasiteye düşen dağıtılmayan sabit genel üretim giderlerinin "satışların maliyeti" kalemine dahil edilmesi sonucunda işletmelerin brüt kar yerine zarar veya gerçekte olması gerekenden düşük kar raporlayacağını belirten yazarlar bunun işletme hakkında yanıltıcı sonuçlar 
doğuracağının altını çizerek bu tespitlerini bir vaka çalışması ile desteklemiş ve bu tutarın "esas faaliyetlerden diğer giderler" kaleminde raporlanmasını önermişlerdir.

\subsubsection{Nitel Araştırma Yöntemini Kullanan Makalenin İçerik Açısından Değerlendirilmesi}

Yılmaz (2017) tarafından hazırlanan makalede TR90 bölgesindeki (Trabzon, Rize, Ordu, Giresun, Artvin ve Gümüşhane) Serbest Muhasebeci Mali Müşavir Oda Başkanlarının BOBİ FRS konusundaki görüşleri 8 soru çerçevesinde değerlendirilmiş ve uygulayıcıların görüşlerinin irdelendiği bir çalışma hazırlanmıştır. Nitel araştırma yöntemlerinden biri olan görüşme tekniği kullanılan bu araştırmada yarı yapılandırılmış mülakat tekniği uygulanarak yüz yüze ve telefon görüşmesi yoluyla mülakat yapılmıştır. Mülakatlar sırasında veriler ses kaydı veya not tutma yöntemi ile elde edilmiştir.

Bu bağlamda, 6 oda başkanından (1) Türkiye'de BOBİ FRS'ye geçişin gerekliliğine, (2) Türkiye'nin BOBİ FRS'ye geçiş için hazır olma durumuna, (3) BOBİ FRS eğitimi konusunda yapılan çalışmaların yeterlilik durumuna, (4) BOBİ FRS eğitimi konusunda sadece KGK'nın yetkili olması durumuna, (5) BOBİ FRS eğitimi konusunda oda olarak izlenen plana, (6) TFRS ve BOBİ FRS konuları ile uyumlu yeni bir Tek Düzen Hesap Planının oluşturulmasına, (7) TFRS ve BOBİ FRS konuları ile uyumlu yeni bir Vergi Usul Kanunu'nun oluşturulmasına ve (8) BOBİ FRS'ye geçişte meslek mensuplarının karşılaşabilecekleri sorunlara ilişkin değerlendirmelerde bulunmaları istenmiştir. Çalışmanın sonucunda oda başkanlarının BOBİ FRS uygulamasına sıcak baktıkları ancak uygulamanın kolay olmayacağına inandıkları tespit edilmiştir.

Çalışmada elde edilen veriler sadece tablolarla aktarılmamış oda başkanlarının her bir konu ile ilgili görüşlerine metinde onların kendi cümleleri çerçevesinde yer verilmiştir.

\subsection{BOBİ FRS Üzerine Literatür İncelemesi Kapsamındaki Makalelerin Aldıkları Atıflar Açısından Değerlendirilmesi}

BOBİ FRS ile ilgili olarak yayınlanan makaleler, daha sonra yazılan bazı makalelere alt yap1 oluşturmuştur. Bu bağlamda, 2017 y1lı sonu itibariyle burada incelenen makalelerin aldıkları atıfların da literatür incelemesi açısından bir veri niteliği taşıdığı düşünülmüştür.

Bu doğrultuda, BOBİ FRS ile ilgili olarak burada incelenen atıflar Google Scholar üzerinden tespit edilen çerçevede aşağıda Tablo 7'de gösterilmiştir.

\section{Tablo 7: BOBİ FRS Literatür İncelemesi ve Alınan Atıflar}

\begin{tabular}{|c|c|}
\hline Makaleler & Aldıkları Atıflar \\
\hline $\begin{array}{l}\text { Gençoğlu, Ü. G. (2017). Temel Konularda } \\
\text { BOBİ FRS ve TMS/TFRS Karş1laştırmas1. } \\
\text { Muhasebe ve Finansman Dergisi,(76): } 1 \text { - } \\
24 .\end{array}$ & $\begin{array}{l}\text { Yılmaz, Z. (2017). TR90 Bölgesindeki } \\
\text { SMMM Oda Başkanlarının BOBI FRS } \\
\text { Konusundaki Görüşleri. Journal of Social and } \\
\text { Humanities Sciences Research. Vol:4/15: } \\
\text { 1866-1880. }\end{array}$ \\
\hline $\begin{array}{l}\text { Doğan, A. (2017). Büyük ve Orta Boy } \\
\text { İşletmeler için Finansal Raporlama } \\
\text { Standardı ile TMS/TFRS Karşılaştırması. } \\
\text { İşletme Araştırmalarl Dergisi, 9(4), 770- } \\
786\end{array}$ & Tespit edilememiştir. \\
\hline Ataman, B., \& Cavlak, H. (2017). Büyük ve & Tespit edilememistir. \\
\hline
\end{tabular}




\begin{tabular}{|c|c|}
\hline $\begin{array}{l}\text { Orta Boy İşletmeler için Finansal } \\
\text { Raporlama Standardı (BOBİ FRS) ile Tam } \\
\text { Set Türkiye Muhasebe ve Finansal } \\
\text { Raporlama Standartlarını (TMS/TFRS) } \\
\text { Karş1laştırılması. Finans Ekonomi ve Sosyal } \\
\text { Araştırmalar Dergisi (FESA), 2(3), 153- } \\
\text { 168. }\end{array}$ & \\
\hline 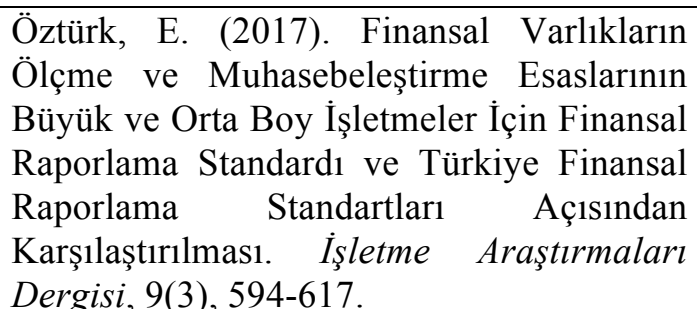 & $\begin{array}{l}\text { Yılmaz, Z. (2017). TR90 Bölgesindeki } \\
\text { SMMM Oda Başkanlarının BOBI FRS } \\
\text { Konusundaki Görüşleri. Journal of Social and } \\
\text { Humanities Sciences Research. Vol:4/15: } \\
\text { 1866-1880. }\end{array}$ \\
\hline $\begin{array}{l}\text { Gökçen, G., \& Öztürk, E. (2017). Tam } \\
\text { Maliyet ve Normal Maliyet Yöntemlerinin } \\
\text { UFRS (TFRS) ve BOBİ FRS'deki } \\
\text { Düzenlemeler Çerçevesinde Incelenmesi. } \\
\text { Finans Ekonomi ve Sosyal Araştırmalar } \\
\text { Dergisi (FESA), 2(2), 105-114. }\end{array}$ & Tespit edilememiştir. \\
\hline $\begin{array}{l}\text { Yılmaz, Z. (2017). TR90 Bölgesindeki } \\
\text { SMMM Oda Başkanlarının BOBİ FRS } \\
\text { Konusundaki Görüşleri. Journal of Social } \\
\text { and Humanities Sciences Research. } \\
\text { Vol:4/15: 1866-1880. }\end{array}$ & Tespit edilememiştir. \\
\hline
\end{tabular}

\section{SONUÇ ve ÖNERILER}

Bu çalışmada, BOBİ FRS ve BOBİ FRS'nin temelini ve taslak metnini oluşturan YFRÇ'ye ilişkin bir literatür incelemesi yapılmıştır. YFRÇ ile ilgili olarak yayınlandığı tespit edilen makale sayısının 9 ile sınırlı kaldığı görülmüştür. Diğer taraftan, Temmuz 2017'de yayınlanan BOBİ FRS'ye ilişkin olarak 2017 yılı sonu itibariyle henüz 6 makalenin yayınlandığı görülmüştür. Yayınlanan makale sayısı oldukça sınırlı olmakla birlikte konunun Türkiye için güncel olması nedeniyle yeni çalışmalar beklenmektedir. Bu doğrultuda, BOBİ FRS ile ilgili olarak gerek muhasebe politikaları açısından gerekse çeşitli çevrelerin BOBİ FRS hakkındaki görüşlerini almak bakımından farklı araştırma yöntemleri kullanan makaleler yazılabilir. Bu doğrultuda, aşağıdaki çalışmalar önerilmektedir:

(1) BOBİ FRS ile KOBİ'ler için UFRS (2015)'in karşılaştırılması,

(2) BOBİ FRS ile paralel statüdeki başka ülke uygulamalarının karşılaştırılması,

(3) BOBİ FRS ile ilgili olarak akademik camianın görüşlerinin tespiti,

(4) BOBİ FRS ile ilgili olarak farklı bölgelerdeki meslek mensuplarının görüşlerinin tespiti ve önceki çalışmalarla karşılaştırılması,

(5) Üniversitelerin işletme, muhasebe gibi ön lisans, lisans ve yüksek lisans programlarında okuyan öğrencilerin BOBİ FRS'ye ilişkin farkındalıklarının tespiti,

(6) BOBİ FRS'nin üniversitelerin işletme muhasebe gibi ön lisans, lisans ve yüksek lisans müfredat programlarına dahil edilmesine ilişkin değerlendirme ve öneriler ile 
(7) BOBİ FRS'deki muhasebe politikalarının yevmiye kaydına ve finansal tablolara dönüştürülmesine rehberlik edecek örnek uygulamalı çalışmalar.

Yukarıdaki önerilerden de görülmektedir ki BOBİ FRS ile ilgili olarak akademik yazında araştırılması gereken konular mevcuttur. Dolayısı ile yukarıda ifade edilen önerilerle sınırlı olmamak üzere BOBİ FRS'ye ilişkin literatüre katkı sağlamak mümkündür.

\section{KAYNAKÇA}

Ataman, B., \& Cavlak, H. (2017). Büyük ve Orta Boy İşletmeler için Finansal Raporlama Standardı (BOBİ FRS) ile Tam Set Türkiye Muhasebe ve Finansal Raporlama Standartlarının (TMS/TFRS) Karşılaştırılması. Finans Ekonomi ve Sosyal Araştırmalar Dergisi (FESA), 2(3), 153-168.

Doğan, A. (2017). Büyük ve Orta Boy İşletmeler için Finansal Raporlama Standardı ile TMS/TFRS Karşılaştırması. Iş̧letme Araştırmaları Dergisi, 9(4), 770-786

Gençoğlu, Ü. G. (2017). Temel Konularda BOBİ FRS ve TMS/TFRS Karşılaştırması. Muhasebe ve Finansman Dergisi,(76): 1-24.

Gökçen, G., \& Öztürk, E. (2017). Tam Maliyet ve Normal Maliyet Yöntemlerinin UFRS (TFRS) ve BOBİ FRS'deki Düzenlemeler Çerçevesinde İncelenmesi. Finans Ekonomi ve Sosyal Araştırmalar Dergisi (FESA), 2(2), 105-114.

Karataş, M. (2016). Yerel Finansal Raporlama Çerçevesi Taslağı ve KOBİ TFRS İle Karşılaştııılması. Vergi Sorunları Dergisi, 39(328), 73.

Kaya, C. T., \& Türegün, N. (2016). Dünyada KOBİ Finansal Raporlama Uygulamaları ve Türkiye için Çıkarımlar: Yerel Finansal Raporlama Çerçevesine Bakış. Muhasebe ve Denetime Bakış, 16(50), 97.

KGK (2017). Büyük ve Orta Boy İşletmeler için Finansal Raporlama Standardı. Ankara: Önka Matbaası

Kılınç, Y. (2016). Yatırım Amaçlı Gayrimenkullerin Türkiye Muhasebe ve Finansal Raporlama Standartları (TMS/TFRS) ile Yerel Finansal Raporlama Çerçevesi Taslağı Açısından Karşılaştırmalı İncelenmesi ve Muhasebeleştirilmesi. Journal of International Social Research, 9(43):1935-1946

Özerhan, Y. (2016). Yerel Finansal Raporlama Çerçevesi Taslağındaki Ölçümleme Esasları Üzerine Bir Değerlendirme, Muhasebe Bilim Dünyası Dergisi, 18 (2), 307336.

Öztürk, C. (2017). The role and current status of IFRS in the completion of national accounting rules-Evidence from Turkey. Accounting in Europe, 14(1-2), 226-234.

Öztürk, E. (2017a). Stok Maliyetlerinin Ölçüm ve Muhasebeleştirme Esaslarının VUK, TMS/TFRS VE YFRÇ Taslağı Açısından Karşılaştırılması. Pamukkale Üniversitesi Sosyal Bilimler Enstitüsü Dergisi, (28): 141-157.

Öztürk, E. (2017b). Finansal Varlıkların Ölçme ve Muhasebeleştirme Esaslarının Büyük ve Orta Boy İşletmeler İçin Finansal Raporlama Standardı ve Türkiye Finansal 
Raporlama Standartları Açısından Karşılaştırılması. İşletme Araştırmaları Dergisi, 9(3), 594-617.

Ünkaya, G., \& Dabbağoğlu, K. (2016). Yerel Finansal Raporlama Çerçevesi Taslağında Önerilen Satış Geliri ve Ticari Alacak Muhasebesi Üzerine Bir Eleştiri. Marmara Üniversitesi Öneri Dergisi, 12(46), 121-136.

Yılmaz, B., Dölen, T., \& Atik, M. (2016). Yerel Finansal Raporlama Çerçevesinin Muhasebe Meslek Mensupları Açısından Değerlendirilmesi: Ankara İli Meslek Mensuplar1 Uygulamas1. Muhasebe ve Vergi Uygulamalari Dergisi (MUVU), 9(3): 297-326.

Yılmaz, Z. (2017). TR90 Bölgesindeki SMMM Oda Başkanlarının BOBİ FRS Konusundaki Görüşleri. Journal of Social and Humanities Sciences Research. Vol:4/15: 1866-1880.

Yünlü, M. (2016). Bağımsız Denetime Tabi Olup TMS/TFRS'leri Uygulama Kapsamında Olmayan İșletmeler İçin Finansal Raporlama Standartları. Muhasebe ve Denetim Dünyası, 1(1), 23-42. 


\title{
Framework for Local Financial Reporting and Financial Reporting Standard for Large and Medium Sized Entities: A Literature Review (2016 - 2017)
}

\author{
Can ÖZTÜRK \\ Çankaya University \\ Faculty of Economics and Administrative Sciences \\ Department of Business Management \\ Ankara, Turkey \\ orcid.org/0000-0003-1587-4707 \\ cozturk@cankaya.edu.tr
}

\section{Extensive Summary}

In Turkey, financial reporting is regulated by Turkish Public Oversight, Accounting and Auditing Standards Authority (TPOAASA) within the framework of the concepts of independent audit and public accountability. For the purpose of financial reporting, entities that are subject to independent audit and publicly accountable are subject to Turkish Financial Reporting Standards (TFRS) that are in compliance with International Financial Reporting Standards; however, entities that are not publicly accountable but subject to independent audit have two options either to use TFRS or Financial Reporting Standard for Large and Medium Sized Entities (FRS for LMEs).

FRS for LMEs that was published by TPOAASA on June 29, 2017 replaced its draft predecessor, Framework for Local Financial Reporting (FLFR). FRS for LMEs is a standalone document which does not make any specific reference to TFRS except for referring to TAS 32 Financial Instruments - Presentation in Section 9 'Financial Instruments and Equity' (Öztürk, 2017, pp. 3) and is made up of 27 Sections.

FRS for LMEs is important in terms of accounting applications in Turkey. It is a financial reporting standard that provides the investors and creditors the opportunity to understand the financial statements of the entities that are subject to independent audit but not publicly accountable and do not prefer using TFRS as well as it provides faithful representation and comparability of financial statements and meets the need of financial information.

The objective is to this paper is to focus on a literature review related to the papers published in referred journals on the recently published FRS for LMEs and its draft predecessor FLFR by considering the years 2016 and 2017 to observe whether authors prepared their research papers on which aspects of financial reporting regarding FLFR and FRS for LMEs. Within the framework of this analysis, this paper offers suggestions for future research.

The paper has the following structure: section 2 and section 3 present the literature review on FLFR and FRS for LMEs, respectively. Finally, section 4 presents concluding remarks along with main findings and suggestions for further research. 
According to the literature review on FLFR, this paper points out that there are 9 papers published in referred journals from the date when FLFR was first published until the date when FRS for LMEs replaced it.

Within this sample of papers, findings show that (1) papers were published by different referred journals, (2) one of the papers was written in English and others were written in Turkish, (3) the majority of authors preferred comparative approach while preparing their papers; however, there are a limited number of other approaches adopted by them, (4) other approaches adopted refer to both comparative and critical approach, empirical approach and descriptive approach, (5) comparative papers make comparative research between FLFR and (a) Turkish General Communiqués on Accounting System, (b) TFRS, (c) European Union's Directive of 2013/34, (d) Turkish Financial Reporting Standard for Small and Medium Sized Entities which is the 2009 version of International Financial Reporting Standard for Small and Medium Sized Entities (IFRS for SMEs) published by International Accounting Standards Board (IASB), and (6) there are a limited number of subject-specific comparative papers which compare FLFR with (a) TFRS from the perspective of investment property accounting, and (b) both Turkish Tax Procedure Law and TFRS from the standpoint of inventories.

In addition, while critical and comparative paper focuses on the recognition of sales revenue and trade receivables, descriptive paper examines the SME accounting from the perspective of IFRS for SMEs in the general context and from the perspective of FLFR in the Turkish context. Empirical paper concludes section 2 by analyzing the views of certified public accountants and sworn-in certified public accounts operated in city of Ankara in terms of FLFR.

On the other hand, according to the literature review on FRS for LMEs, this paper points out that there are 6 papers published in referred journals so far from the date when FRS for LMEs was first published until the end of the year 2017.

Within this sample of papers, findings show that (1) papers were published by different referred journals, (2) all papers were written in Turkish, (3) the majority of authors preferred comparative approach while preparing their papers; however, there are a limited number of other approaches adopted by them, (4) other approaches adopted refer to both comparative and critical approach and qualitative approach, (5) comparative papers make comparative research between FRS for LMEs and TFRS and complement each other from different perspectives, and (6) there is one subject-specific comparative paper which compare FRS for LMEs and TFRS with each other from the perspective of the presentation and recognition of financial assets.

In addition, while critical and comparative paper focuses on inventories with a particular focus on normal absorption costing and full costing, qualitative paper concludes section 3 by analyzing the views of certified public accountants operated in TR90 region (cities of Trabzon, Gümüşhane, Rize, Ordu, Giresun, and Artvin) in terms of FRS for LMEs.

While concluding the paper, it should be noted a very limited number of papers regarding the discussion on the draft FLFR were written. On the other hand, it is expected that new papers will be published on the FRS for LMEs due to the fact that this is a current and trend topic in Turkish accounting arena. In this context, it is possible to write new papers not only related to the accounting policies of FRS for LMEs but also related to the views of several parties on FRS for LMEs by using 
different research methods. As a result of this paper, the following topics for potential research papers were offered:

(1) Comparative research between FRS for LMEs and IFRS for SMEs (2015),

(2) Comparative research between FRS for LMEs and similar practices of other countries,

(3) The views of Turkish accounting academics on FRS for LMEs,

(4) The views of certified public accountants on FRS for LMEs in different regions of Turkey and comparison of these views with prior research,

(5) The awareness of the business and accounting students related to FRS for LMEs at the vocational, undergraduate and graduate level university education,

(6) Evaluation and suggestions on the integration of FRS for LMEs to the business and accounting curriculum of vocational, undergraduate and graduate level university education, and

(7) Applied case studies that will guide the users of FRS for LMEs to recognize its accounting policies and to prepare FRS for LMEs based financial statements.

As it is seen from the suggestions above, there are still a number of possible research topics related to FRS for LMEs. That is why it possible to contribute to the accounting literature, including but not limited to the topics mentioned above. 